Tizian Zumthurm*

\title{
Crowdsourced COVID-19 Collections: A Brief Overview
}

https://doi.org/10.1515/iph-2021-2021

Published online July 12, 2021

\begin{abstract}
This article provides an overview of how public historians and other actors collect material on the global COVID-19 pandemic. Their common goal is to archive a diversity of perspectives to document these historic times. Focusing on initiatives that collect from a broader public and that incorporate some sort of crowdsourcing, I distinguish between two approaches: projects that collect something specific and projects that formulate their call more openly. The article discusses the strengths and weaknesses of each approach, what opportunities they open up, and what limits they impose on future research on the pandemic. The 10 selected case studies are based in 10 different countries, represent the variety of institutions that are involved in participatory collecting, and have all published their collections online and are thus useful for teaching and research worldwide.
\end{abstract}

Keywords: COVID-19, pandemic, archive, public collecting, crowdsourcing history

Future historians carrying out research on everyday life during the COVID-19 pandemic may well be overwhelmed with the amount of material at their disposal. This article might therefore be helpful for them. However, it is also intended to be of immediate use for scholars interested in a variety of contemporary issues and in how to archive material in ways that includes the public. ${ }^{1}$

The obvious problem was how to select the projects to be presented in a short overview paper. The best approach was a pragmatic one. Since I wanted to ensure that the paper

1 I would like to thank David Dean for his guidance in conceptualizing this article, Stefan Krebs for his helpful inputs on a draft of this paper, and the two reviewers for their useful comments. Sarah Cooper has done a great job in proofreading the text. Research on this article was supported by the Covid-19 fast-track grant 14704989 of the Luxembourg National Research Fund (FNR).

*Corresponding author: Tizian Zumthurm, Postdoctoral Researcher, Public History, Luxembourg Centre for Contemporary and Digital History $\left(\mathrm{C}^{2} \mathrm{DH}\right)$, Esch-sur-Alzette, Luxembourg,

E-mail: tizian.zumthurm@uni.lu

Ә Open Access. (C) 2021 Tizian Zumthurm, published by De Gruyter. ((c) BY License. would be useful in teaching and research for a worldwide audience, I only considered projects whose products or results are accessible online, although they come from as many different countries as possible. In addition, in order to acknowledge the participatory aspect of public history, I chose projects that involve some sort of crowdsourcing, by which I mean that (parts of) the public are actively involved in the creation of collections with their personal material, as opposed to, for example, analogue or digital collecting done by members of an institution or web crawlers. The main downside of these criteria is that they rule out many libraries and archives. It should be stressed that the latter are especially engaged in much of the innovative work being produced in order to document these times. ${ }^{2}$

The first place to look for public history projects on COVID-19 is two online maps. One is dually maintained by the International Federation of Public History and Made by Us, a collaborative to bring history to young people. The other one is part of a "broader research project on the impact of COVID-19 on museum digital strategies"3 at the University of Graz. Unlike the IFPH map, which lists initiatives from all sorts of institutions, the latter only includes museums, but has the advantage of providing filters. For our purposes, the most useful filter is "contemporary collecting projects:" most of the others, such as "virtual tours" or "educational content, " are not specifically related to COVID-19. Both of these maps have a bias towards North America and Western Europe that is obvious at first sight. The overall value of maps like these is simultaneously their main problem: they generate visibility for any projects that are pinned there and obscure any that are not.

From these maps, I selected 10 projects for their diversity in terms of approach and geography. They are based in 10 different countries on five continents, but six of them come from Europe. ${ }^{4}$ The reason for this bias is not only my personal standpoint and the overrepresentation of

2 WARCnet provides a good overview of the activity of various national archives in Europe.

3 "About," Museum digital initiatives during the Coronavirus Pandemic, accessed April 28, 2021, https://digitalmuseums.at/about. html.

4 I am unable to present a project from Asia because they are in scripts that I cannot read. There are public collection projects by, for example, the National Taiwan Museum of History or Kansai University in Japan. 
the region on the above-mentioned maps; it is also to ensure a more balanced representation of institutional backgrounds: while five of the initiatives were launched at universities, three are from museums, one from an archive, and one from a library.

This diversity provides many different points of view on the global pandemic, but is not without its problems. The sheer number of projects, and even more so their multitude of perspectives, scopes, themes, and technical solutions, make broader analytical comparisons difficult. Moreover, most collecting efforts remain local or national, and thus transnational questions will be challenging to tackle. Having said that, it is important to recognize that it is the online availability of various global collections which opens up possibilities for comparative research in the first place.

The initiatives are presented in pairs to enable some degree of comparison and to propose research questions, with occasional references to additional projects in footnotes. I distinguish between two approaches to collecting. The first six projects gather more specific material in terms of theme or form, while the last four issued a more open call for material.

\section{Collecting Specific Answers}

The projects presented in this section asked specific questions to a selected group of individuals about how they experienced the pandemic. This was done through various means, including by telephone, video, or email. In general, this way of collecting requires more time and organization than others and thus there are comparatively few initiatives that opt for this approach. ${ }^{5}$

5 The NHS at 70 project at the University of Manchester switched to telephone interviews at the start of the pandemic and asked participants, for example, what their first memory of COVID-19 was. The New Zealand Ministry for Culture \& Heritage encouraged people to produce their own oral histories and provided a list of questions, for instance: what were people doing during lockdown or what were they hoping to achieve during this time. In Australia, the State Library Victoria launched a Memory Bank and posted a weekly theme for five months. Starting with "what's in your fridge?", the themes also included "design a poster or compose a slogan to promote public safety through the pandemic" and ended with "what do you want people in 100 years from now to know about this time?" People could send in their responses via Facebook, from where they are now difficult to retrieve. None of these initiatives has so far published the contributions in a systematic way, which means that we cannot tell how successful they were.
The Lockdown Diaries from Cape Town is a WordPress blog by political studies scholars at the University of the Western Cape and international development scholars at the University of Edinburgh. Seventy people from Cape Town share their experiences via structured WhatsApp interviews. Between April and July 2020, the researchers chose 26 current developments and some more general themes to formulate 3-6 specific questions for each. The topics range from schooling or the ban on smoking and drinking to crime or trust in government. The blog has very good information on the participants with details about their age and gender and the type of settlement they live in. Their anonymity is protected, but it is unclear how they were selected.

The diaries or answers are not published in full, but rather appear as summarized texts with long quotations. These give voice to the participants and provide a considerable number of perspectives and themes, while allowing the reader to identify the most important issues. In addition, the research team has published 10 texts that analyze the contributions. They reflect, for example, on the impact of the South African social grants, on how the pandemic affected the inequalities of the school system, and on the political economy of rumors in the city. In its analytical dimension, the platform goes further than most other COVID-19 collections.

Between June and August 2020, the Repository of Didactic Material for History Teaching (REMADIH) at the University of Alfenas in Brazil published a series of structured written interviews with 35 participants, many of whom have a university background. They had the possibility of remaining anonymous, but most of them agreed to provide information about their age, gender, race, profession, and place of origin. All of them answered the same five questions: What do you think you will remember about the pandemic? And what do they want to forget? What has changed in their relationship with people close to them and with the environment, including forms of housing and means of consumption? What is their routine during the pandemic? Finally, participants were asked to write five words that define this moment for them.

As opposed to the Lockdown Diaries, which are rather unusual in this regard, it is less easy to identify topics of common concern in the Alfenas project. But the fact that all replies are to the same questions allows for more openness in analysis and easy comparison. The questions are precise enough to trigger meaningful responses, while still allowing a diverse array of topics to be addressed. These two case studies show that the main advantage of structured interviews is obtaining insights that are more vivid and detailed than with other forms of collecting. At the 
same time, this approach already puts forward a certain narrative about the pandemic, as the interviewer determines the content at least to some degree. ${ }^{6}$

\section{Collecting Specific Objects or Events}

Another approach to archiving COVID-19 material is to ask people for specific items or experiences that are connected to the pandemic. Many museums opt for this approach; most do not collect objects themselves, but rather photographs featuring objects. A number of platforms asked people to share pictures of public documents, such as government regulations or posters in bars and shops. Often these initiatives are very local in scope, but there are exceptions. ${ }^{7}$

From the Alpinarium comes one example of the countless projects run by small-town museums. Located in Galtür, a municipality with less than 800 inhabitants in the Austrian region of Tyrol, the Alpinarium has asked people to send in selfies of themselves wearing a mask. On its website, the museum has published almost 200 pictures, many of which are more formal portraits rather than selfies. The online collecting form is very brief and simple, which lowers the barrier to contribute. It comes at a cost, however, in that there is no additional information about the photos, such as date or place.

The mask is a typical and recurring object in many collections on the pandemic, at least in the West. It would

6 For discussions on the role of narratives in crowdsourced history and memory studies see: Mark Hedges and Stuart Dunn, Academic Crowdsourcing in the Humanities: Crowds, Communities and Co-Production (Cambridge: Chandos Publishing, 2017), especially Chapter 8; Timothy Recuber, "The Prosumption of Commemoration: Disasters, Digital Memory Banks, and Online Collective Memory," American Behavioral Scientist 56, no. 4 (2012): 531-49; Pedro Telles da Silveira, "From Instant History to the Infinite Archive: Digital Archiving, Memory and the Practical Past at the Roy Rosenzweig Center for History and New Media," Historein 17, no. 2 (2018). doi: https://doi.org/10. 12681/historein.10964.

7 The hashtag \#vitrinesenconfinement, based at Paris Nanterre University, invites people to send pictures of windows in public spaces. The platform is national in scope, but has received a considerable number of contributions from beyond France among its more than 3000 photos (roughly two-thirds of which are published). The Museum Fronfeste in Neumarkt am Wallersee (a town with ca. 6400 inhabitants in Austria) similarly asked for public signs, but also personal emails and other things. They have published almost 100 contributions on an external website. be interesting to analyze whether this is also true for other regions, especially Asia. While masks may have become tedious to some by now, the background of the photos at the Alpinarium or additional objects that people pose with can be interesting for historians of everyday life. In addition, this widespread concern with masks by collectors and contributors alike is of historical significance itself as it can tell us and future historians something about how societies and individuals respond to public health measures and challenges.

Hunter Living Histories asked its community to document how they celebrated 2020 Anzac Day at home. The commemoration of fallen soldiers from the Australian and New Zealand Army Corps could not be celebrated as usual with public dawn services and ceremonies; instead, it had to be held in private yards. Hunter Living Histories is an initiative about community history and conservation in Australia's Hunter Region and is based at the University of Newcastle Library's Cultural Collections. Personal testimonies of Anzac at home could be shared by email and the institution published approximately 75 contributions from about 40 contributors. ${ }^{8}$ People revealed their names and mostly shared photographs with short descriptions and information on where they were taken, but some also offered longer reflections.

Like the above project on masks, this initiative illustrates how people react to public health measures. Since the day was celebrated among families in private yards, masks were largely absent. The broader theme of moving public and private gatherings to the home is, of course, rather persistent on a global level. Many entries on more open platforms deal with how people spent national or religious holidays and birthdays. This opens up transnational comparisons of how commemorative events have changed during the pandemic. At the same time, Hunter Living Histories and the Alpinarium show how valuable it can be for an institution to be locally grounded for generating testimonies. ${ }^{9}$

8 It is a common observation in crowdsourcing projects that comparatively few users contribute a disproportionate amount of the material (Trevor Owens, "Digital Cultural Heritage and the Crowd," Curator: The Museum Journal 56, no. 1 (2013): 121-30; Hedges and Dunn, Academic Crowdsourcing).

9 The role of locality (spatial and social) in crowdsourcing merits further attention. For a preliminary discussion in a business context see: Andreas Mladenow, Christine Bauer, Christine Strauss, and Michal Gregus, "Collaboration and Locality in Crowdsourcing” (paper presented at the International Conference on Intelligent Networking and Collaborative Systems, Taipai, Taiwan, September 2-4, 2015). doi: https://doi.org/10.1109/INCoS.2015.74. 


\section{Collecting from Specific Groups}

The projects in this section gather views on the pandemic from a clearly demarcated target group that is not defined geographically. Given the rich outcome, it is, in retrospect, a pity that very few institutions opted for such an approach. The two initiatives are also unusual in their international scope. ${ }^{10}$

The Artists Respond project was established in April 2020 by the Virtual Museum of Avant-Garde. Based in Croatia, it is a free platform focusing on Eastern and Central Europe and the region's global connections. Sixty artists from all over the world responded to the museum's general call "to virtually present the thoughts and attitudes of neo-avant-garde artists, their energy and the message they have for the present moment." 11 Thumbnails of the artistic responses form the visual center of the website. The contributions can be found in better quality within the individual portraits of the artists on the bottom of the page under the small and somewhat misleading heading "news." These portraits provide detailed information about the responding artists and their work. Many of the artists do not only display one or more pieces of art, but also offer a glimpse into their life, problems, and reflections during the pandemic.

Cov19: Chronicles from the Margins, institutionally based at the University of Swansea in Wales, describes itself as an "arts-based digital ethnography."12 The team consists of 11 people, with artists and socio-cultural facilitators as well as academics from various disciplines including literature, sociology, and development studies, but no historians. They generate material to "understand what life is like during the Covid-19 pandemic from the perspectives of creative asylumseekers, refugees and migrants in the UK and around the world." ${ }^{13}$ The items are published in a gallery consisting of 48 videos (artistic and documentary), 51 photos (sorted by topics), 31 word art contributions, 10 audio recordings (music,

10 The House of European History collects objects and narratives from across the continent, for example rainbow banners or photographs of closed borders. The Journal of the Plague Year (see last section) has collections on the LGBTQ community and on Jewish Melbourne. It is also an example of how difficult it is to convey an international approach. Despite having almost 14,000 items in its collection with archives from Australia, Canada, Latin America (in fact mostly from Peru), and the Philippines, its map only features roughly 5300 contributions, about 4000 of which are from the USA.

11 “'Artists Respond' project," Museum of Avant-Garde, accessed April 28, 2021, http://www.avantgarde-museum.com/en/museum/ projects/artists-respond-project/.

12 "Aims and Objectives," COV19: Chronicles from the Margins, accessed April 28, 2021, https://cov19chronicles.com/4907-2/.

13 "Creatively Chronicling Covid19," COV19: Chronicles from the Margins, accessed April 28, 2021, https://cov19chronicles.com/. performances, and testimonies), and 13 drawings and paintings. Recently, they have launched a digital exhibition with rooms on themes that are relevant to most COVID-19 collections: home, food, faith, community, care, creativity, garden, and walking. Finally, there is a vibrant blog that continues to be active to this day, unlike many other projects that ceased activities after the first wave.

Even more so than the other projects presented in this paper, these two raise the question of the degree to which such collections can be considered public history. The answer will probably depend on the definitions ascribed to the field by those who encounter said collections. In their explanation of the Artists Respond project, the initiators interestingly refer to both the public and history: "We wish for the public to welcome the creative energy of these artists - artists who are ready to point out the state of things, to respond with art and creativity, as they have done in all difficult times in the past." ${ }^{\prime 4}$ Like the other collections, these artistic ones are useful for teaching and research on the pandemic, not only from a historical perspective. More centrally, they share the interactive principle and overall concern of preserving testimonies of people and their everyday experiences.

\section{Collecting Through an Open Call}

Probably the most frequent way of collecting material on the COVID-19 pandemic is via an open call to the public. In this manner, people can decide themselves what to document. Given the nature of digital collecting, the material is often archived as photographs, but there are some institutions that preserve objects. ${ }^{15}$

14 “'Artists Respond' project," Museum of Avant-Garde, accessed April 28, 2021, http://www.avantgarde-museum.com/en/museum/ projects/artists-respond-project/.

15 In late March 2020, the Wien Museum launched a call for photos of objects that exemplify changes in private and professional life. On its website, it published 235 out of the 6000 photos received. In June, it started to gather the physical objects to store and recorded the stories related with them. People can still propose material. The Western Development Museum in Saskatchewan, Canada, hosts a simple crowdsourced exhibition with roughly 150 pictures on how the province views the global pandemic. Via an online form, people can upload photos and write something about them. The National Museum of Australia has created "Bridging the Distance - Sharing our COVID-19 Pandemic Experiences," a public Facebook group where people are encouraged to share personal stories and experiences. The Library of the University of Chile has grouped their own 173 contributions in the following categories: photos, videos, letters/texts, drawings, audios, memes. A Google account is necessary to share these. 
Il Museo della Quarantena stands out among the many examples of open collecting by smaller museums because of its careful approach to esthetics. It is an initiative of the Tridentine Diocesan Museum in central Trento, a city with roughly 120,000 inhabitants in Italy. It has received over 180 contributions so far, which can be sent by email, Facebook Messenger, or private Instagram message. Each one comes with a date, a short description, and a name or pseudonym. The project displays the items online as if they were artistic or archeological objects and there has been an outdoor exhibition with printouts in the same design. The website is great to look at and browse through, but there is no search engine and the contributions do not have tags.

Mémoires de Nantes confinée is, to my knowledge, the only initiative by an archive that publishes what it collects. The municipal archive of this French city with 314,000 inhabitants gathers contributions via email or Instagram hashtag. It has mostly received photos, but also some texts and videos. Like many other platforms of this kind, the archive does not indicate details like place and date. Most contributors remain anonymous, but they provide a longer or shorter description of their entry. Some pictures pop up several times in slightly different versions or with different captions. It is not clear what exactly is being published, as the site does not always load the same number of images. The platform illustrates that not every technical solution is equally suitable or transparent when it comes to archiving contributions from the public and presenting them online in a wellarranged manner.

In such open collections, contributors decide what is important and worthy of archiving. This allows researchers to detect patterns and to compare overall developments from which they can draw broader conclusions. One difficulty will be to find the right tools and methods to carry out such an analysis, given the variety of technical solutions. More importantly, we need be aware that no collection process can be absolutely open. Framing matters greatly and the use of social media, for example, favors those who use such platforms.

\section{Collecting with Omeka S}

This last section presents two projects that collect through an open call using Omeka S, a content management system developed at the Roy Rosenzweig Center for History and New Media. Omeka S is tailored for digital exhibitions and has often been used for rapid response collections. The projects enable everyone to upload and largely construct their entries themselves, with curators subsequently reviewing and publishing them. The map view that is usually incorporated gives users an immediate overview of the number of items and where they come from. These initiatives are often based at universities and have a national or institutional focus. ${ }^{16}$

One of the major COVID-19 crowdsourced archives is the Journal of the Plague Year, launched at Arizona State University. It probably forms the world's largest collection on the pandemic, with over 14,000 items from various affiliated initiatives and a curatorial team of "more than 300 archivists, faculty, staff, students, teachers, and public history practitioners and organizations." 17 One of their collections is the Carleton Covid-19 Archive from the liberal arts college of the same name in Northfield, a town with 20, 000 inhabitants in Minnesota. The project is a collaboration between the archive and various outreach programs of the college and has received over 400 contributions so far. It frames its mission in terms of public history to explain why such projects matter: public history not only "weaves the historian into the narrative," it also "offers a way of engaging critically with the past while never losing sight of our roles in creating the future."18

Like many of the projects affiliated with the Journal of the Plague Year, the curators of the Carleton COVID-19 Archive actively collect and reach out to the community members in order to generate contributions. Often, this process includes students who not only curate public submissions but also produce entries themselves, gather material, and design exhibitions. The site features $17 \mathrm{col}-$ lections and 4 exhibits. The former group the contributions by various topics or entry type, such as travel, generational disparities, articles from the college magazine, or community photos. The latter provide reflections and context on specific themes, for example historic pandemics in the area, using items from the collection. In addition, you can

16 For an overview of the platforms from Austria, Germany, Portugal, and Switzerland, see: Marco Gabellini and Tizian Zumthurm, "Collaborative COVID-19 Memory Banks: History and Challenges," The Luxembourg Centre for Contemporary and Digital History, last modified January 19, 2021, accessed April 28, 2021, https://www.c2dh. uni.lu/thinkering/collaborative-covid-19-memory-banks-history-andchallenges.

17 "NCPH-Peer-Review-Roundtable," The Journal of the Plague Year, accessed April 28, 2021, https://covid-19archive.org/s/archive/page/ ncph.

18 "Welcome to the Carleton Covid-19 Archive," Carleton Covid-19 Archive, accessed April 28, 2021, https://covid19archive.sites.carleton. edu/. 
browse the items by tag or via a map and there is a search function.

The project covidmemory.lu, which I help maintain, is based at the Luxembourg Centre for Contemporary and Digital History $\left(\mathrm{C}^{2} \mathrm{DH}\right)$ and has a comparatively passive approach to collecting; there are no curators who approach individuals or groups and ask them to contribute. Like similar projects, we posted advertisements in public spaces and on social media and gave interviews to newspapers, radio, and television. So far, we have acquired roughly 340 contributions, about 330 of which are published. The main reason for not publishing a contribution has been that there was no obvious connection with the pandemic. Possible copyright infringements were of only minor concern and hate speech or racism have not been an issue. Like most Omeka $\mathrm{S}$ initiatives, a map, in our case combined with a timeline, facilitates browsing. When the site is relaunched in May/ June 2021, it will feature exhibitions on peculiar items, like a series of drawings and cartoons, or topics of broader interest, like homeschooling. It will also host collections from other projects, for example oral history testimonies with various health care representatives carried out by members of the $\mathrm{C}^{2} \mathrm{DH}$ and other institutions, such as the collection of COVID-related objects gathered by Luxembourg's National Museum of History and Art. We are still thinking about the best way to assign and integrate tags to facilitate research and retain a clear structure.

When it comes to the content of the contributions on covidmemory.lu, we were surprised by the high number of items with a creative spin and by the fact that many had a rather positive perspective on the situation. Looking through the other projects presented in this paper, especially those with an open call, I observed similar patterns. These need to be nuanced in the future through more indepth analyses, but a few thoughts are worth formulating. Social groups close to the initiators of the projects appear to be overrepresented. These individuals often had the privilege of being able to use the unexpected spare time generated by pandemic measures in creative and mindful ways. It seems to me to be equally important that many collecting initiatives resemble social media platforms in their structure and framing, especially in their common focus on ego-documents, which encourages socialmedia-like self-presentation. Besides excluding those that do not use Facebook or Instagram, this approach tends to produce more of the same kind of contributions. It runs the risk of creating a series of individualistic stories rather than encouraging users to engage with a variety of emerging narratives and create a multiplicity of accounts.
The collections' resemblance to social media also explains why, across all collections, the first wave generated many more contributions. Over time, "corona fatigue" spread and people had nothing new to say. This lack of novelty makes social-media-like self-presentation a less attractive option.

\section{Conclusion}

The variety of crowdsourced COVID-19 archives is impressive, in terms of their technical solutions, approaches to collecting, as well as the spatial and thematic scopes they have adopted. The projects presented in this paper illustrate that local undertakings that are spatially or socially close to the envisioned participants can generate plentiful historical material from a broader public. Contributors worldwide are concerned with the very tangible effects of political decisions on public and private life and are happy to document their own reactions to these decisions. These dynamics are of central importance to historians of everyday life in general and to public historians in particular.

Engaging with the creation, maintenance, display, and analysis of crowdsourced archives on the pandemic thus fosters reflections on public historians' role in society and on the nature of the field. When they establish and study such collections on current issues, especially when they contextualize these in the form of exhibitions, scholars (including historians) provide preliminary narratives. While so doing, they are reminded of their role in creating the future, to use the words of our colleagues at Carleton College. ${ }^{19}$ In this way, the pandemic has had a considerable impact on the discipline of history, which is often wary of presentism.

If they are to be of real use for future research, collections have to be accessible; they have to be maintained and archived in the long term. Such sustainability is crucial, but it is not easy to achieve. ${ }^{20}$ Alongside this basic issue, a delicate problem of most crowdsourced COVID-19 collections is that many gaps remain. Several social groups and nonconformist or skeptical views remain

19 "Welcome to the Carleton Covid-19 Archive," Carleton Covid-19 Archive, accessed April 28, 2021, https://covid19archive.sites. carleton.edu/.

20 Christine Barats, Valérie Schafer, and Andreas Fickers, "Fading Away ... The Challenge of Sustainability in Digital Studies," Digital Humanities Quarterly 14, no. 3 (2020). http://www.digitalhumanities. org/dhq/vol/14/3/000484/000484.html. 
underrepresented. The same is true for people that have contracted the disease. While future historians on the pandemic will find plenty of material on various aspects of everyday life, at least from specific social groups, they might have trouble finding documentation on official decision-making processes. In some countries, archivists criticize the focus on crowdsourcing everyday experiences. This emphasis takes away the responsibility of archives to document political processes and prevents the creation of collections on issues that might be more relevant in the future. ${ }^{21}$ But it is always difficult to predict the future, even for public historians. 